\title{
Surpporting Information
}

\section{AuNCs-Catalyzed Hydrogen Selenide Oxidation: Mechanism and Application for Headspace Fluorescent Detection of Se(IV)}

Jing Xiong, ${ }^{\dagger}$ Kailai Xu, ${ }^{*, \dagger}$ Xiandeng Hou, ${ }^{\dagger}, \ddagger$ Peng Wu ${ }^{*, \dagger, \ddagger}$

${ }^{\dagger}$ College of Chemistry, ${ }^{\star}$ Analytical \& Testing Center, and "State Key Laboratory of Hydraulics and Mountain River Engineering, Sichuan University, Chengdu, 61004, China

*Corresponding Authors'E-mails: xukailai@scu.edu.cn, wupeng@scu.edu.cn 


\section{Table of contents}

Experimental Section -S3

Figure S1. UV-vis absorption and fluorescence emission spectra of BSA-AuNCs—S5

Figure S2. UV-vis absorption and fluorescence emission spectra of GSH-AuNCs---S6

Figure S3. UV-vis absorption spectrum of uncapped AuNPs$-S 6$

Figure S4. Fluorescence spectra of GSH-AuNCs in the presence of increasing amounts of $\mathrm{H}_{2} \mathrm{Se}$ S6

Figure S5. Effect of deoxygenation on the fluorescence response of S, Se and Te.----S7

Figure S6. Geometric parameters (bond lengths in $\AA$ ) of species in the reaction of

$\mathrm{H}_{2} \mathrm{Se}$ and $\mathrm{O}_{2}$ on the $\mathrm{Au}_{38}$ cluster $-S 7$

Figure S7. Effect of the concentration of $\mathrm{HCl}$ on the fluorescence response----------S8

Figure S8. Effect of the concentration of $\mathrm{KBH}_{4}$ on the fluorescence response--------S8

Figure S9. Effect of the reaction time on the fluorescence response-------------------S9

Figure S10. Effect of the sample volume on the fluorescence response----------------S9

Figure S11. Effect of the concentration of AuNCs on the fluorescence response----S10

Figure S12. Photographs of the bottles containing different amounts of Se(IV) and

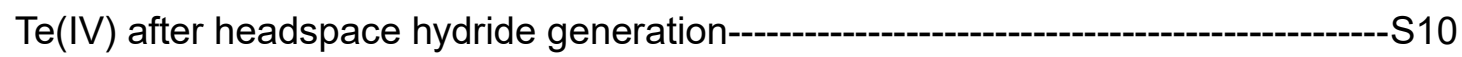

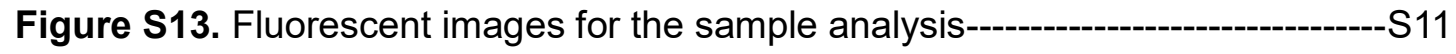

Table S1. Comparison of performance of the proposed assay with other similar ones-S12 


\section{Experimental Section}

Instrumentation. Fluorescence spectra were recorded on an F-7000 spectrofluorometer (Hitachi, Japan) equipped with a solid sensing cell. Scanning electron microscopy (SEM) was performed with a JSM-7500F scanning electron microscope (JEOL, Tokyo, Japan). X-ray photoelectron spectroscopy (XPS, PHI-5000 Versa Probe, ULVAC-PHI) was used to determine the valent state of the AuNCs before and after reaction with $\mathrm{H}_{2} \mathrm{Se}$. Fluorescence imaging was carried out with a gel image analysis system (JK02S, Beijing Junyi Electrophoresis Instrument Factory, F-2) equipped with a $365 \mathrm{~nm}$ reflected UV source. A commercial two-channel hydride generation nondispersive atomic fluorescence spectrometer (AFS-9600, Beijing Haiguang instrumental Co., Beijing, China) was used for the detection of the intensity of the selenium atomic fluorescence. A microwave synthesizer (UWave-1000, Shanghai sineo Microwave Chemistry Technology Co., China) was used to synthesize AuNCs.

Synthesis of GSH-AuNCs and 5-nm AuNPs. The water-soluble GSH-AuNCs were synthesized following the method as described in the literature. ${ }^{1}$ GSH aqueous solution $(0.30 \mathrm{~mL}, 100 \mathrm{mM})$ and $\mathrm{HAuCl}_{4}$ aqueous solution $(1.00 \mathrm{~mL}, 20 \mathrm{mM})$ mixed with $8.70 \mathrm{~mL}$ of ultrapure water at room temperature, and the mixture was under gentle stirring at $70{ }^{\circ} \mathrm{C}$ for $24 \mathrm{~h}$ followed by cooling to room temperature naturally. Then the final pale-yellow GSH-AuNCs solution was kept at $4{ }^{\circ} \mathrm{C}$ prior to use.

AuNPs were synthesized according to reference. ${ }^{2}$ A $20 \mathrm{~mL}$ aqueous solution containing $2.5 \times 10^{-4} \mathrm{M} \mathrm{HAuCl}_{4}$ was prepared in an around bottomed flask at room temperature, then $0.6 \mathrm{ml}$ of ice cold $0.1 \mathrm{M} \mathrm{NaBH}_{4}$ was added to the above solution under stirring. The solution turned to orange-red color immediately after adding $\mathrm{NaBH}_{4}$, indicating particle formation. 
Sample preparation. A microwave digestion method was used to digest DOLT-5, DORM-4, selenium-enriched rice and selenium-enriched egg. Rice sample was washed three times with ultra-pure water and dried in an oven at $60{ }^{\circ} \mathrm{C}$ for $30 \mathrm{~min}$. Then rice was grounded into powder. Subsequently, $0.125 \mathrm{~g}$ DOLT-5, $0.5 \mathrm{~g}$ DORM-4, $2 \mathrm{~g}$ selenium-enriched rice and $2 \mathrm{~g}$ selenium-enriched egg were accurately weighed into precleaned Teflon vessels and then $8 \mathrm{~mL}$ of $\mathrm{HNO}_{3}$ and $2 \mathrm{~mL}$ of $\mathrm{H}_{2} \mathrm{O}_{2}$ were added. The sample blanks were processed along with the samples. The sealed vessels were heated in a microwave oven (Multiwave PRO, Shanghai Sineo Microwave Chemistry Technology Co., China) operated under the following conditions: $10 \mathrm{~min}$ at $700 \mathrm{~W}$ and $100{ }^{\circ} \mathrm{C}, 15 \mathrm{~min}$ at $1000 \mathrm{~W}$ and $150{ }^{\circ} \mathrm{C}$, and $25 \mathrm{~min}$ at $1400 \mathrm{~W}$ and $200{ }^{\circ} \mathrm{C}$. After cooling, the digested products were transferred into Teflon crucibles and continued to heat the remaining volume to $2 \mathrm{~mL}$ or so, must not be steamed to dryness. After cooling, added $5 \mathrm{~mL} \mathrm{HCl}(6 \mathrm{~mol} / \mathrm{L})$ to the digested products and heated to almost dry. $\mathrm{Se}(\mathrm{VI})$ was then reduced to $\mathrm{Se}(\mathrm{IV})$. The residues were transferred to precleaned $10 \mathrm{~mL}$ volumetric flasks with 5\% (v/v) $\mathrm{HCl}$ and added to the mark. Tap water and seawater sample added in hydrochloric acid were directly reacted with $\mathrm{KBH}_{4}$ without microwave digestion.

Computational details. All of the calculations were carried out by employing DFT methods in the $\mathrm{Dmol}^{3}$ software of the Materials studio package. ${ }^{3,4}$ The generalized gradient approximation (GGA) with the PW91 function was used. ${ }^{5-7}$ Localized double numerical plus polarization (DNP) basis sets were applied to expand the Kohn-Sham orbitals. These numerical basis sets are similar to $6-31 \mathrm{G}(\mathrm{d}, \mathrm{p})$ in size, but tend to be more accurate than the latter and have little basis set superposition error (BSSE). The core electrons of the metal atoms were treated using density functional semicore pseudopotentials (DSPP), which include scalar (mass-velocity and Darwin) relativistic corrections for the core electrons. A real-space cutoff of $4.5 \AA$ was used, which is 
sufficient for accurate evaluation of the energies. The selfconsistent field (SCF) calculations have been done with a convergence criterion of $10^{-6} \mathrm{Ha}$ on the total energy. All the SCF calculations were carried out with spin unrestricted and symmetry not enforced to allow for full geometry relaxation. The value of smearing is 0.005 Hartree.

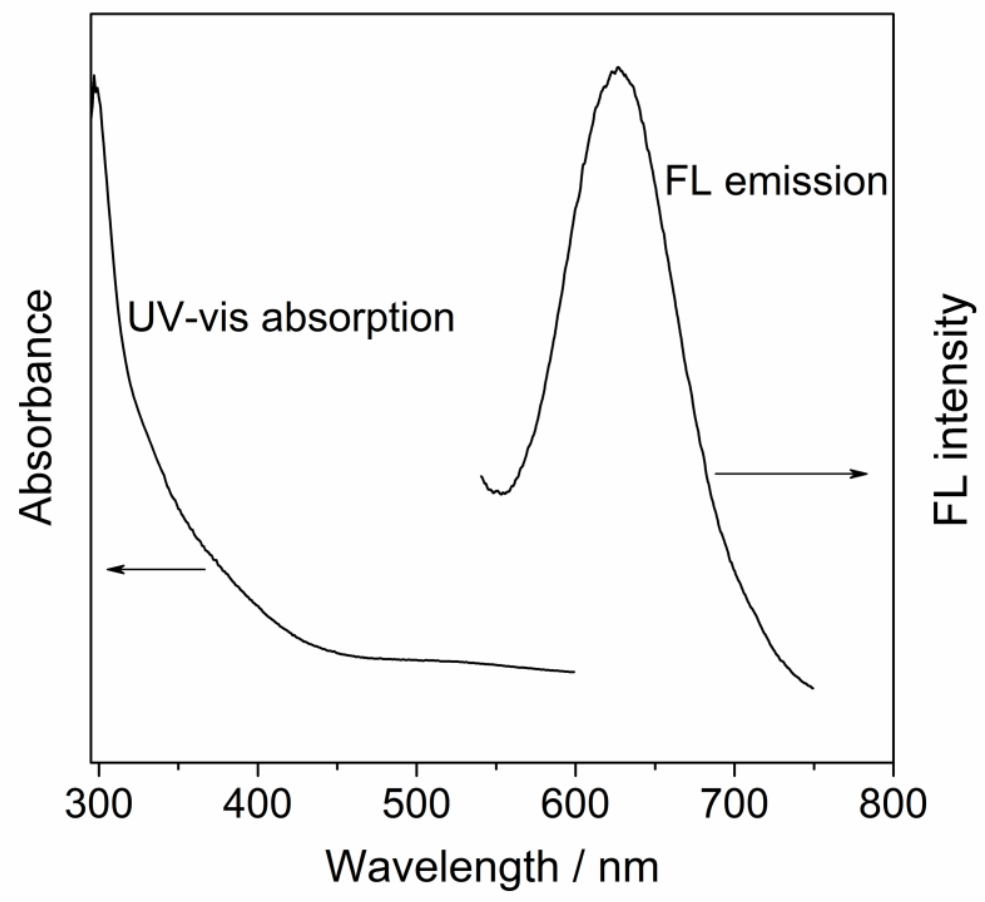

Figure S1. UV-vis absorption and fluorescence emission spectra of BSA-AuNCs. 


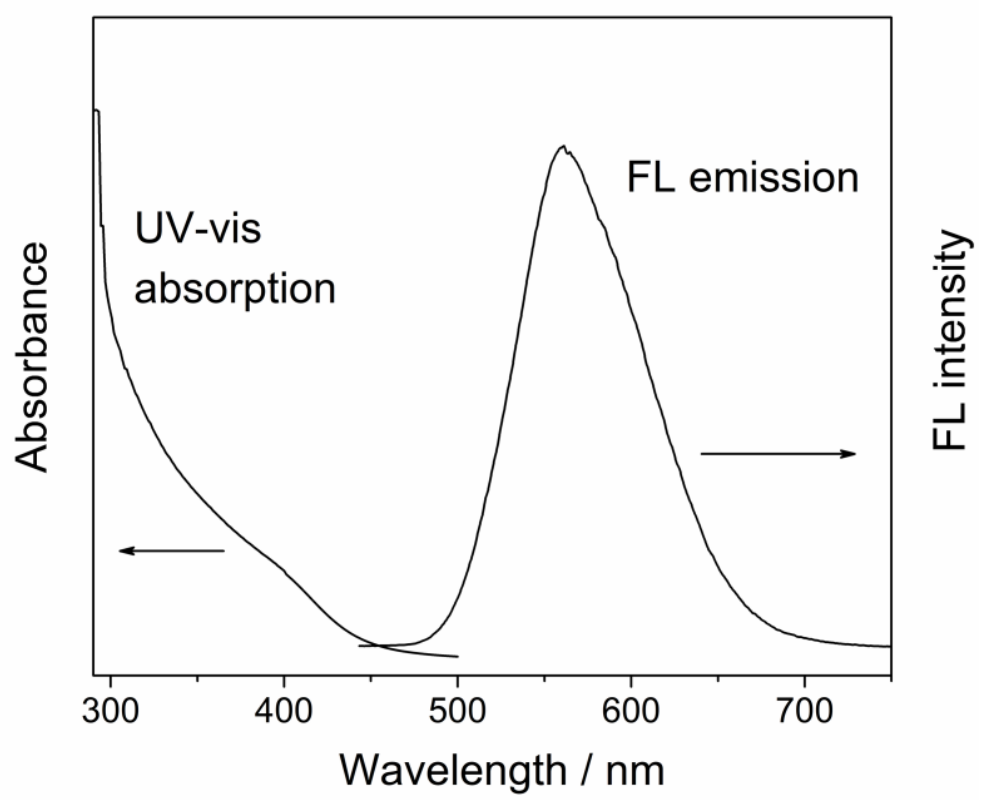

Figure S2. UV-vis absorption and fluorescence emission spectra of GSH-AuNCs.

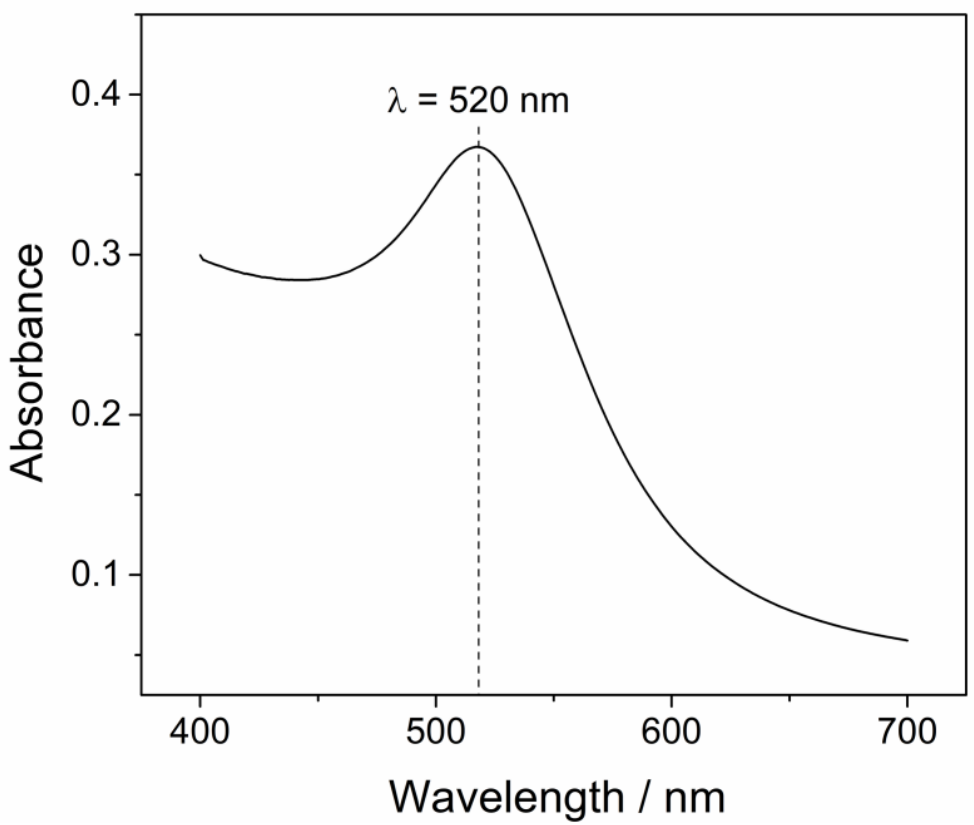

Figure S3. UV-vis absorption spectrum of uncapped AuNPs. 


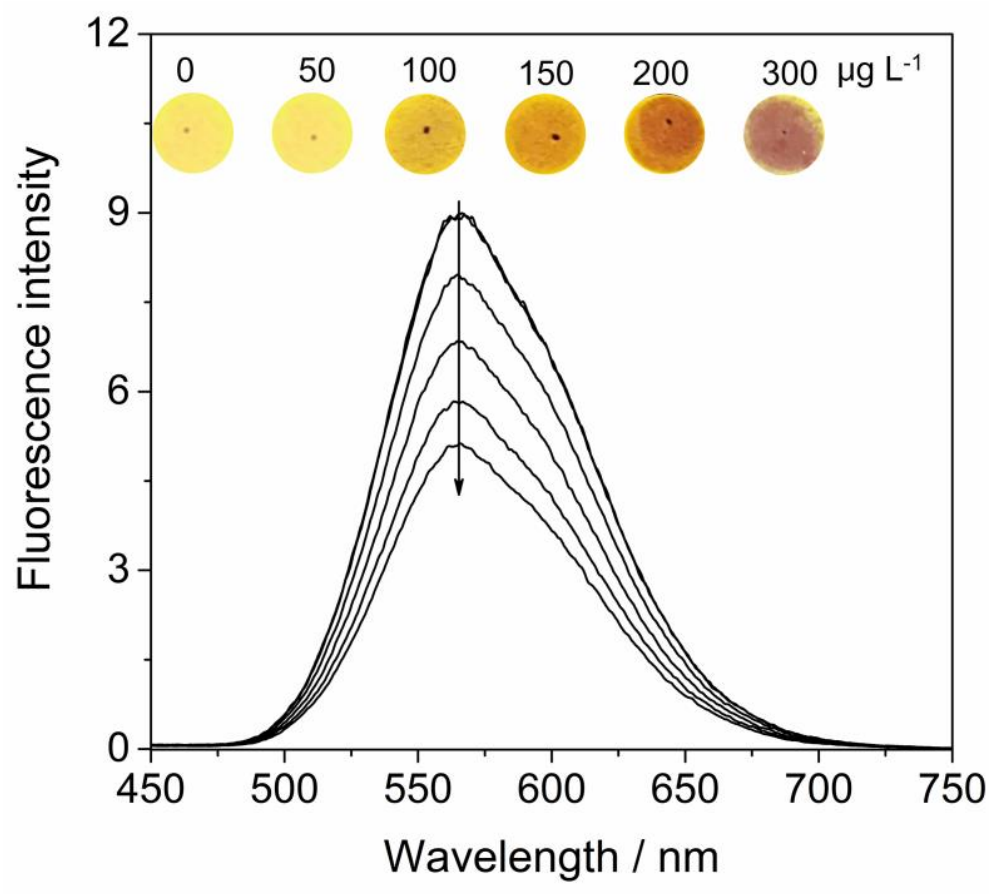

Figure S4. Fluorescence spectra of GSH-AuNCs in the presence of increasing amounts of $\mathrm{H}_{2} \mathrm{Se}$. The inset shows the corresponding fluorescent images.

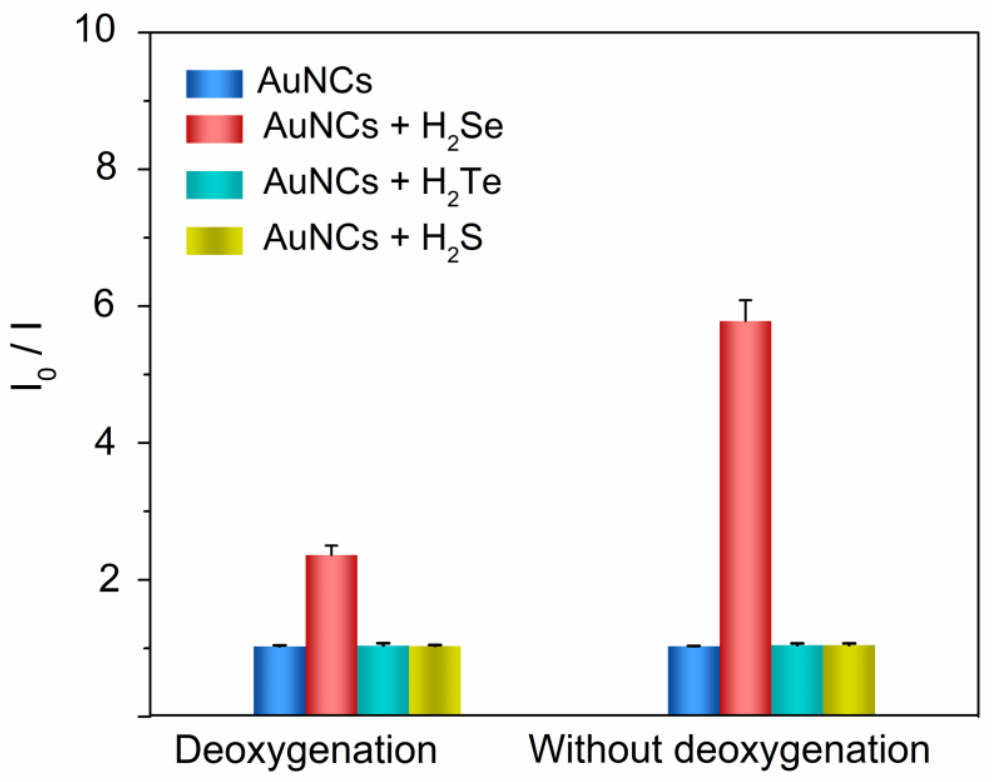

Figure S5. Effect of deoxygenation on the fluorescence response of S, Se and Te. 


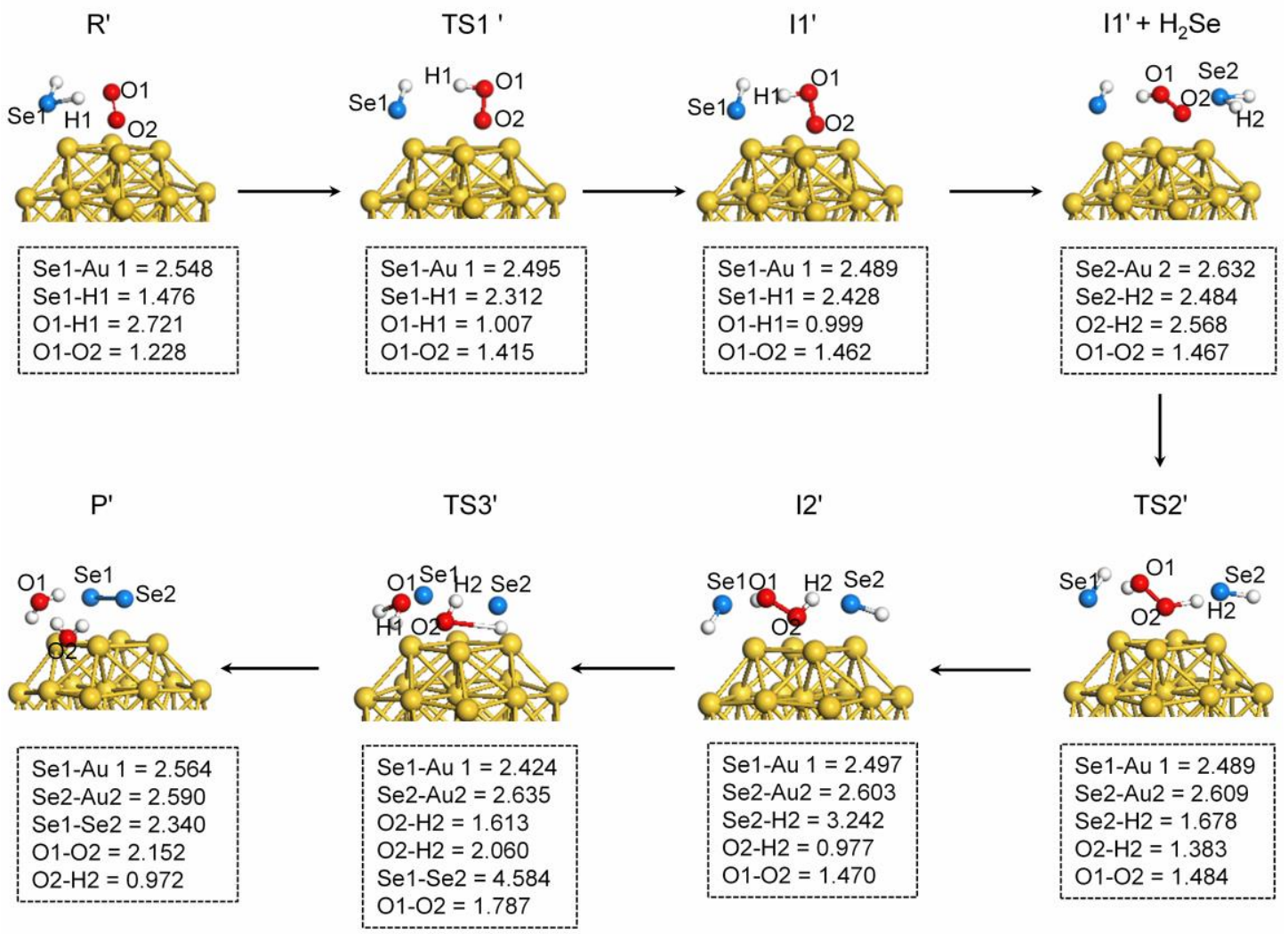

Figure S6. Geometric parameters (bond lengths in $\AA$ ) of species in the reaction of $\mathrm{H}_{2} \mathrm{Se}$ and $\mathrm{O}_{2}$ on the $\mathrm{Au}_{38}$ cluster.

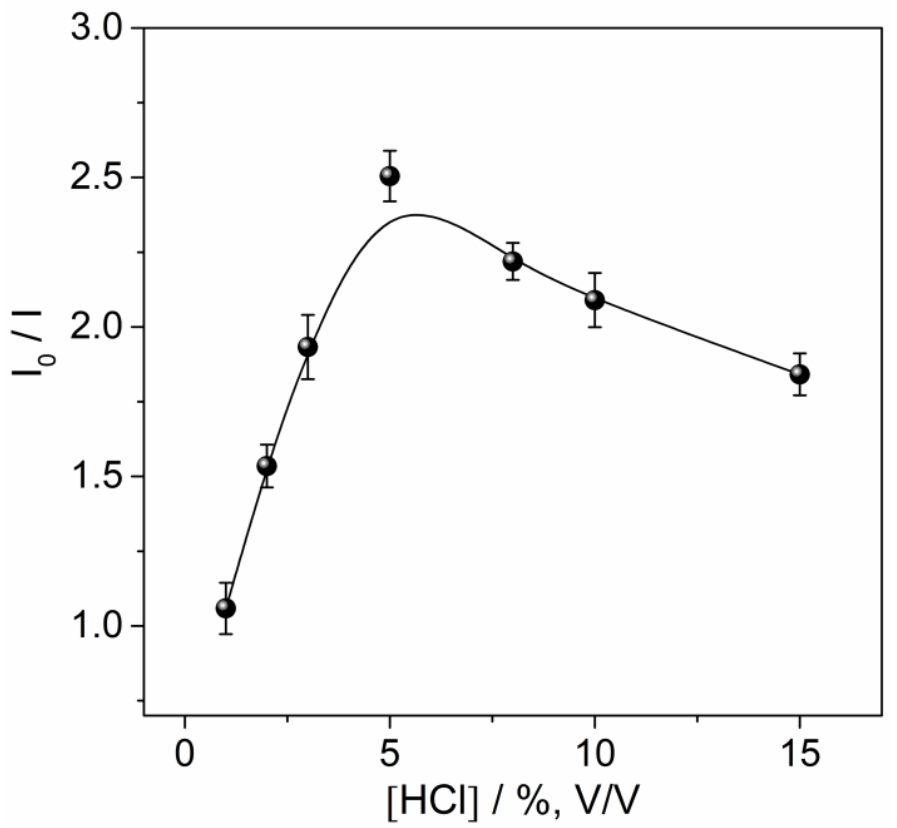

Figure S7. Effect of the concentration of $\mathrm{HCl}$ on the fluorescence response. Experimental conditions: concentration of Se(IV), $100 \mu \mathrm{g} \mathrm{L}^{-1}$; concentration of AuNCs, $2.5 \mathrm{mM}$; concentration of $\mathrm{KBH}_{4}, 3 \%(\mathrm{~m} / \mathrm{v})$; sample volume: $10 \mathrm{~mL}$; reaction time: $20 \mathrm{~min}$. 


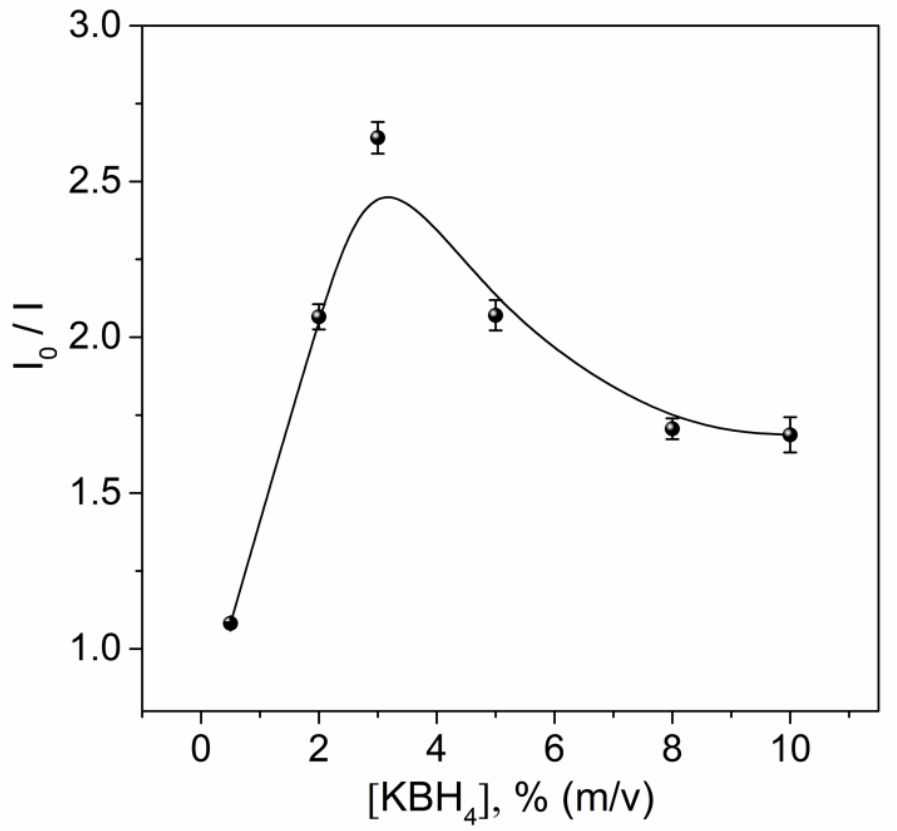

Figure S8. Effect of the concentration of $\mathrm{KBH}_{4}$ on the fluorescence response. Experimental conditions: concentration of $\mathrm{Se}(\mathrm{IV}), 100 \mu \mathrm{g} \mathrm{L}^{-1}$; concentration of AuNCs, $2.5 \mathrm{mM}$; concentration of $\mathrm{HCl}, 5 \%(\mathrm{v} / \mathrm{v})$; sample volume: $10 \mathrm{~mL}$; reaction time: $20 \mathrm{~min}$.

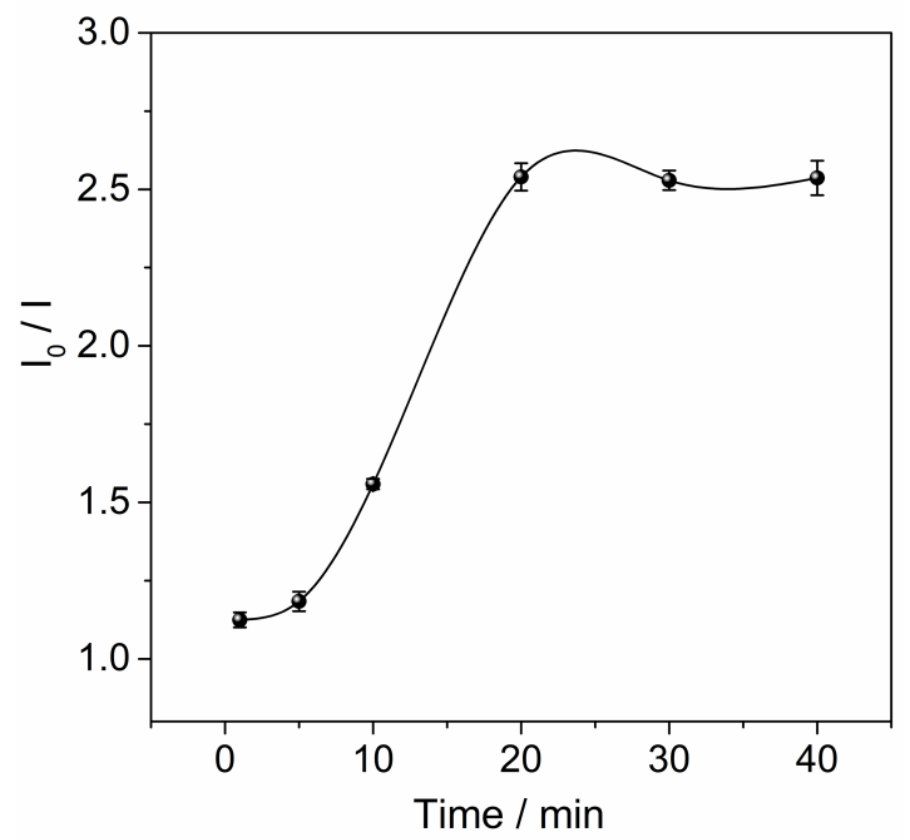

Figure S9. Effect of the reaction time on the fluorescence response. Experimental conditions: concentration of $\mathrm{Se}(\mathrm{IV}), 100 \mu \mathrm{g} \mathrm{L}^{-1}$; concentration of AuNCs, $2.5 \mathrm{mM}$; concentration of $\mathrm{HCl}, 5 \%(\mathrm{v} / \mathrm{v})$; concentration of $\mathrm{KBH}_{4}, 3 \%(\mathrm{~m} / \mathrm{v})$; sample volume: $10 \mathrm{~mL}$. 


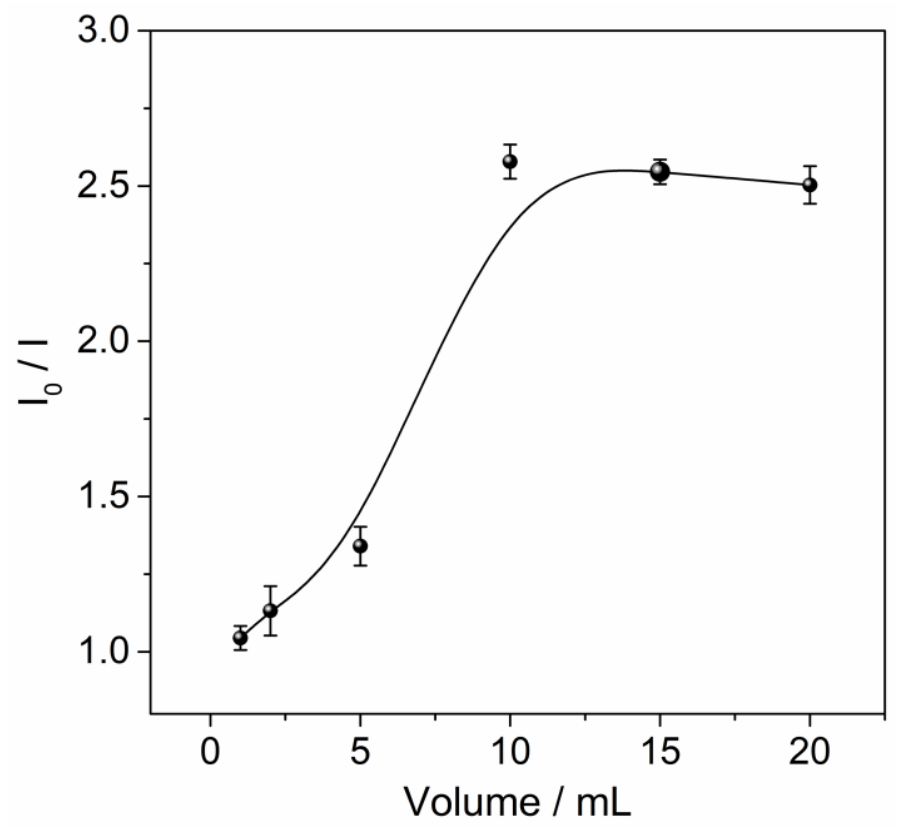

Figure S10. Effect of the sample volume on the fluorescence response. Experimental conditions: concentration of $\mathrm{Se}(\mathrm{IV}), 100 \mathrm{\mu g} \mathrm{L}^{-1}$; concentration of AuNCs, $2.5 \mathrm{mM}$; concentration of $\mathrm{HCl}, 5 \%(\mathrm{v} / \mathrm{v})$; concentration of $\mathrm{KBH}_{4}, 3 \%(\mathrm{~m} / \mathrm{v})$; reaction time: $20 \mathrm{~min}$.

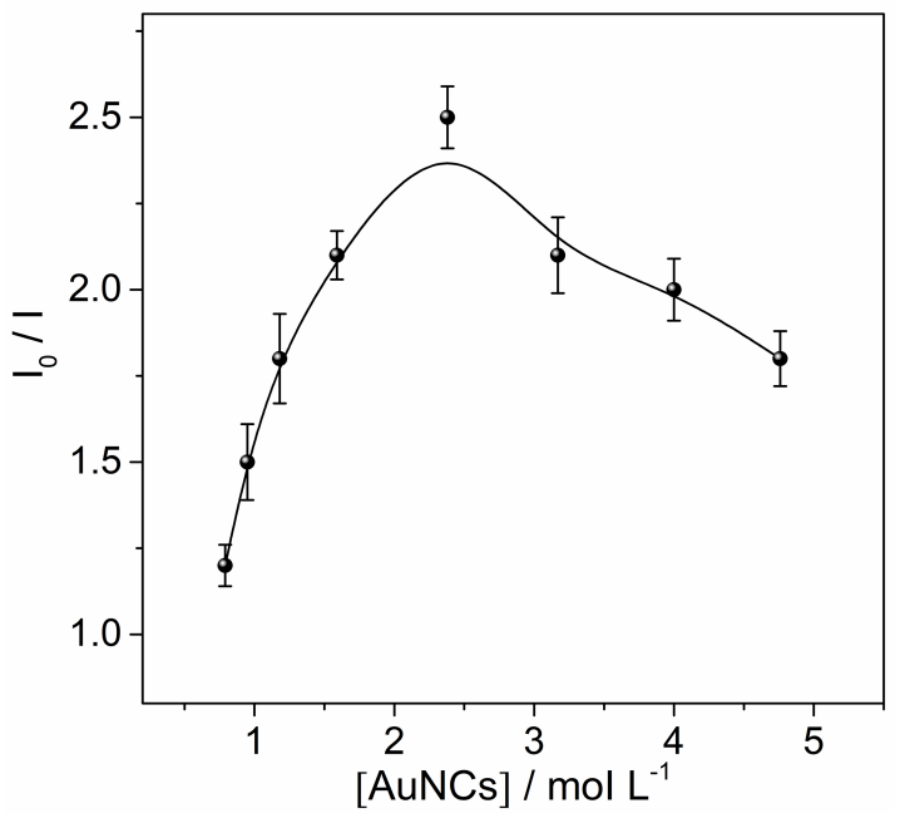

Figure S11. Effect of the concentration of AuNCs on the fluorescence response. Experimental conditions: concentration of $\mathrm{Se}(\mathrm{IV}), 100 \mu \mathrm{g} \mathrm{L}^{-1}$; concentration of $\mathrm{HCl}, 5 \%$ $(\mathrm{v} / \mathrm{v})$; concentration of $\mathrm{KBH}_{4}, 3 \%(\mathrm{~m} / \mathrm{v})$; sample volume: $10 \mathrm{~mL}$; reaction time: $20 \mathrm{~min}$. 


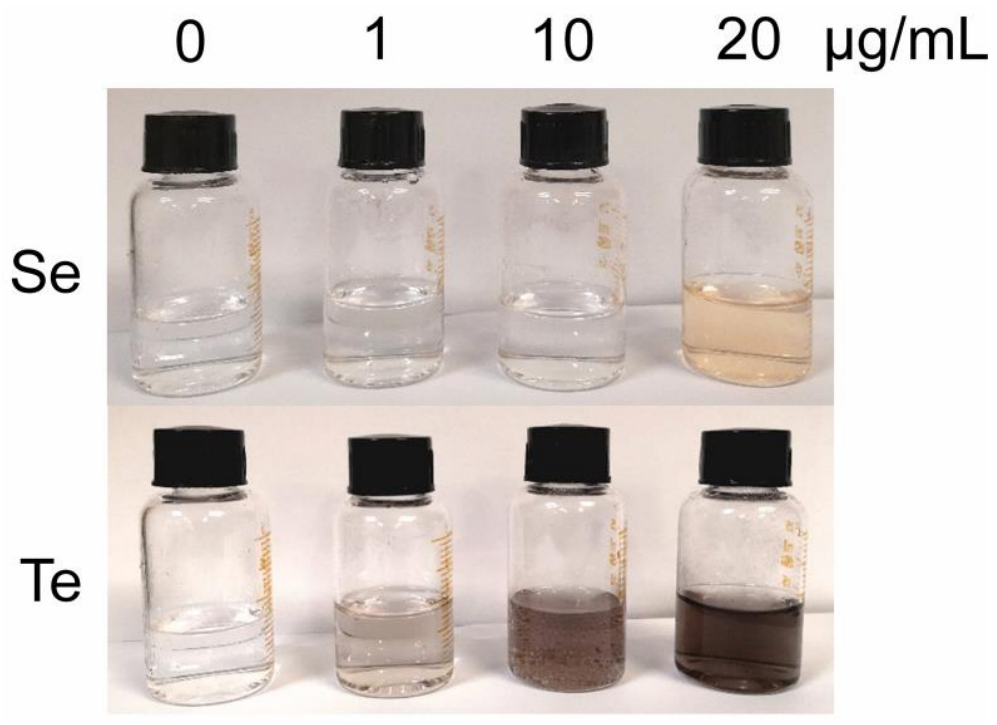

Figure S12. Photographs of the bottles containing different amounts of $\mathrm{Se}(\mathrm{IV})$ and $\mathrm{Te}(\mathrm{IV})$ after headspace hydride generation.

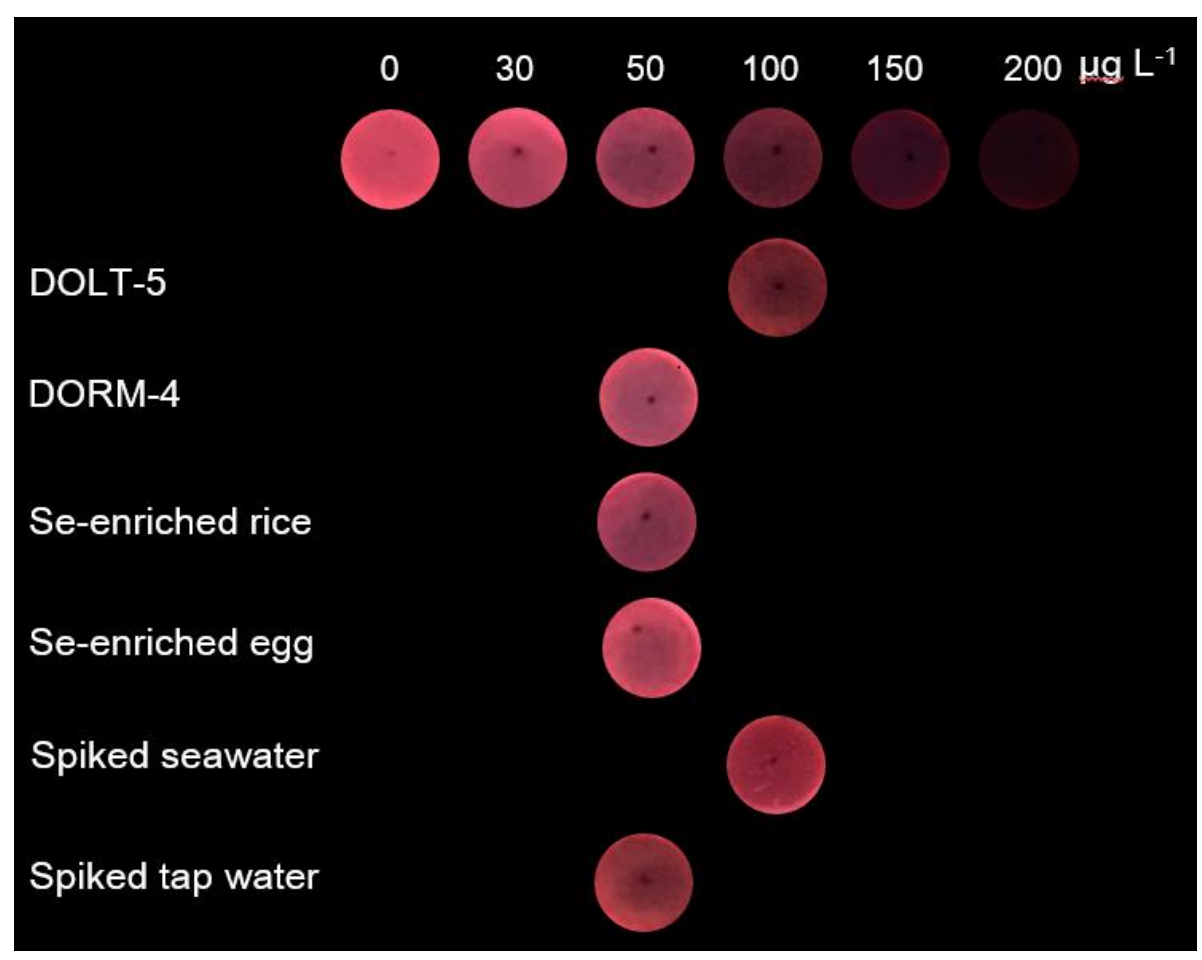

Figure S13. Fluorescent images for the sample analysis. 
Table S1. Comparison of performance of the proposed assay with other similar ones

\begin{tabular}{|c|c|c|c|c|c|}
\hline method & $\begin{array}{l}\text { linear upper } \\
\text { limit } \\
\left(\mu \mathrm{g} \mathrm{L}^{-1}\right)\end{array}$ & $\begin{array}{c}\text { limits of } \\
\text { detection } \\
\left(\mu \mathrm{g} \mathrm{L}^{-1}\right)\end{array}$ & $\operatorname{RSD}(\%)$ & sample & ref. \\
\hline $\begin{array}{l}\text { AuNPs-FI- } \\
\text { HG-Uv-vis }\end{array}$ & $31.6-316$ & 3.95 & - & Se-rich egg & 8 \\
\hline $\begin{array}{l}\text { OQDs-HG- } \\
\text { SPE- FS }\end{array}$ & $5-100$ & 0.1 & 2.4 & human urine & 9 \\
\hline $\begin{array}{l}\text { QD-HS- } \\
\text { SDME }\end{array}$ & $50-750$ & 12.6 & 5.0 & tap water & 10 \\
\hline $\begin{array}{l}\text { QDs-HS- } \\
\text { SDME- } \mu \text { FS }\end{array}$ & $5.0-65.0$ & 0.08 & 4.6 & $\begin{array}{c}\text { Lake water } \\
\text { seawater }\end{array}$ & 11 \\
\hline $\begin{array}{l}\text { HS-SDME- } \\
\text { ETAAS }\end{array}$ & - & 0.15 & 2.5 & seawater & 12 \\
\hline $\begin{array}{l}\text { HS-ETV- } \\
\text { ICP-MS }\end{array}$ & $0.05-20.00$ & 0.008 & 7.0 & Human hair & 13 \\
\hline FI-HG-AAS & $2.5-10.0$ & 0.2 & 6.3 & $\begin{array}{c}\text { river } \\
\text { sediment }\end{array}$ & 14 \\
\hline $\begin{array}{l}\text { AuNCs-HG- } \\
\text { SPE-FS }\end{array}$ & $30-200$ & 4.0 & 2.8 & $\begin{array}{l}\text { Se-rich rice } \\
\text { Se-rich egg }\end{array}$ & This work \\
\hline \multicolumn{6}{|c|}{$\begin{array}{l}\text { FI, flow injection; SD, single drop; HG, hydride generation; SPE, Solid-Phase Extraction; FS, fluoro- } \\
\text { spectrometry; HS-SDME, headspace single-drop microextraction; } \mu \mathrm{FS} \text {, microfluorospectrometry; } \\
\text { ETAAS, electrothermal atomization-atomic absorption spectrometry; ETV-ICP-MS, electrothermal } \\
\text { vaporization inductively coupled plasma-mass spectrometry; AAS, atomic absorption spectrometry. }\end{array}$} \\
\hline
\end{tabular}




\section{References}

(1) Chen, Y. S.; Kamat, P. V. J. Am. Chem. Soc. 2014, 136, 6075.

(2) Gole, A.; Murphy, C. J. Chem. Mater. 2004, 16, 3633.

(3) Delley, B. Journal of Chemical Physics 1990, 92, 508.

(4) Delley, B. Journal of Chemical Physics 2000, 113, 7756.

(5) Perdew, J. P.; Burke, K.; Ernzerhof, M. Phys. Rev. Lett. 1996, 77, 3865.

(6) Perdew, J. P.; Burke, K.; Wang, Y. Phys.rev.b 1998, 57, 84377.

(7) Burke, K.; Perdew, J. P.; Wang, Y. Derivation of a Generalized Gradient Approximation: The PW91 Density Functional; Springer US, 1998.

(8) Cao, G.; Xu, F.; Wang, S.; Xu, K.; Hou, X.; Wu, P. Anal Chem 2017, 89, 4695.

(9) Huang, K.; Xu, K.; Zhu, W.; Yang, L.; Hou, X.; Zheng, C. Anal Chem 2016, 88, 789.

(10) Costas-Mora, I.; Romero, V.; Pena-Pereira, F.; Lavilla, I.; Bendicho, C. Anal Chem 2011, 83, 2388.

(11) Costas-Mora, I.; Romero, V.; Pena-Pereira, F.; Lavilla, I.; Bendicho, C. Anal Chem 2012, 84, 4452.

(12) Fragueiro, S.; Lavilla, I.; Bendicho, C. Talanta 2006, 68, 1096.

(13) Xiong, C.; Hu, B. Talanta 2010, 81, 578.

(14) Zhang, Y.; Adeloju, S. B. Talanta 2008, 76, 724. 